\title{
Cultural Expectations of Muscularity in Men: The Evolution of Playgirl Centerfolds
}

\author{
Richard A. Leit, ${ }^{1 *}$ Harrison G. Pope, Jr., ${ }^{2,3}$ and James J. Gray ${ }^{1}$ \\ ${ }^{1}$ Department of Psychology, American University, Washington, DC \\ ${ }^{2}$ Biological Psychiatry Laboratory, McLean Hospital, Belmont, Massachusetts \\ ${ }^{3}$ Department of Psychiatry, Harvard Medical School, Boston, Massachusetts \\ Accepted 12 July 1999
}

\begin{abstract}
Objective: We sought to assess whether cultural ideals of the male body, as illustrated by magazine models, have changed over the past 25 years. Method: We examined 115 male centerfold models in Playgirl magazine from 1973 to 1997. Using the models' heights and weights quoted by the magazine, together with visual estimates of body fat, we calculated the body mass index (BMI) and fat-free mass index (FFMI) of each model. Results: The Playgirl centerfold models became increasingly "dense" and more muscular over time, as indicated by the significant correlations between BMI, FFMI, and year of publication. Discussion: These observations, in combination with previous studies, suggest that cultural norms of the ideal male body are growing increasingly muscular. (O) 2000 by John Wiley \& Sons, Inc. Int J Eat Disord 29: 90-93, 2001.
\end{abstract}

Key words: male body image; media; muscularity; models

\section{INTRODUCTION}

It is widely believed that our society's ideal of the female body has grown steadily thinner over the years. In an ingenious test of this hypothesis, Garner, Garfinkel, Schwartz, and Thompson (1980) analyzed Playboy magazine centerfold models and Miss America Pageant contestants from 1959 to 1978. They found that the ideal female body, as represented by both of these measures, became progressively thinner over the 20-year period. A follow-up study found that this trend continued between 1979 and 1988: Miss America contestants continued to become thinner, whereas Playboy centerfolds fell to a plateau of very low body weight (Wiseman, Gray, Mosimann, \& Ahrens, 1992).

Fewer studies have examined the evolution of society's ideal for the male body. In one study of male and female magazines for 18-24-year-olds, Andersen and DiDomenico

\footnotetext{
Portions of this paper were presented at the annual meeting of the Eastern Psychological Association, Providence, RI, April 1999.

${ }^{*}$ Correspondence to: Richard Leit, Department of Psychology, American University, 4400 Massachusetts Avenue, NW, Washington, DC 20016.
}

(c) 2000 by John Wiley \& Sons, Inc. 
(1992) found that men's magazines published significantly more advertisements and articles about changing body shape than about losing weight, suggesting that men might be more concerned with overall physique than with fat. Another study found that between 1980 and 1991, men's fashion magazines printed an increasing number of articles on men's weight and health concerns (Nemeroff, Stein, Diehl, \& Smilack, 1994). A third study noted a trend for the greater use of young male bodies in fashion magazines and in marketing a variety of products (Davis, Shapiro, Elliot, \& Dionne, 1993). In another study examining the evolution of boys' action toys, Pope, Olivardia, Gruber, and Borowiecki (1999) found that figures such as GI Joe have become increasingly muscular over time, with many contemporary figures having physiques more muscular than is humanly attainable.

These trends in cultural ideals for body image may contribute to psychopathology. Among women, it has been hypothesized that cultural ideals of thinness may contribute to the rising prevalence of eating disorders (Garner et al., 1980; Wiseman et al., 1992). Among men, cultural ideals of muscularity may contribute to lower self-esteem about the body (Blouin \& Goldfield, 1995; Pope, Gruber, Choi, Olivardia, \& Phillips, 1997; Leit, 1998) and possibly to abuse of anabolic-androgenic steroids (Pope \& Katz, 1994).

To augment the available data on trends in cultural ideals of male body image, we followed the strategy of Garner et al. (1980) and Wiseman et al. (1992) described above, but instead examined the dimensions of Playgirl centerfold models over the magazine's 25-year history.

\section{METHOD}

Playgirl, a magazine focused on male beauty, has been published continuously since 1973 and currently enjoys a circulation of about 300,000 (McFarland, 1988). We examined all of the Playgirl magazines between 1973 and 1997. In 115 (38\%) of the 300 issues, the height and weight of the centerfold men were published in the magazine. Multiple photographs of each of these 115 men were presented in random order to a blinded rater (HGP), who estimated the body fat of each man on the basis of the pictures. This rater had extensive past experience in estimating body fat from images (Kouri, Pope, Katz, \& Oliva, 1995; Gruber, Pope, Borowiecki, \& Cohane,1998). We then calculated each man's body mass index $\left(B M I=\mathrm{kg} / \mathrm{m}^{2}\right.$ ) and fat-free mass index (FFMI; Kouri et al., 1995). The FFMI provides a more direct estimate of muscularity because it eliminates body fat by calculating the lean BMI and then adding a small correction for height:

$$
\mathrm{FFMI}=\mathrm{W} \times((1-\mathrm{BF}) / 100) / \mathrm{H}^{2}+6.1 \times(1.8-\mathrm{H}),
$$

where $\mathrm{W}=$ total body weight in kilograms, $\mathrm{H}$ = height in meters, and $\mathrm{BF}=$ percent of body fat. An FFMI of 20 is approximately average for an American man, 22 represents a distinctly muscular man, and 25 represents approximately the upper limit of muscularity attainable without use of anabolic steroids.

We calculated Pearson correlations between the year of publication and the models' BMI, percent of body fat, and FFMI.

\section{RESULTS}

The centerfolds' BMI was positively correlated with the date, $r=.29, p<.01$, which indicates that the centerfolds became more "dense" over time. However, their percent of 
body fat was negatively correlated with the date, $r=-.34, p<.01$. Thus, their muscularity, as reflected by FFMI, increased even more sharply over time than the BMI, $r=.38, p<.01$.

In addition, 8 of the 115 models had an FFMI of greater than 25. Two of these models were from the 1980s and 6 from 1994 and later. Thus, it appears that the most muscular models (who likely attained their body shape through the use of steroids) were largely from the most recent years.

\section{DISCUSSION}

Our analysis of Playgirl centerfold models augments the growing evidence that the cultural norm for the ideal male body has become increasingly muscular over the years, especially during the 1990s. These findings appear congruent with other observations of trends in the ideal male body image in our society, as reflected in magazines (Andersen \& DiDomenico, 1992; Nemeroff et al., 1994), action toys (Pope et al.,1999), and in other media. Although the cause of this trend is not certain, the discovery and dissemination of anabolic steroids may be a factor (Kouri et al., 1995). Another possibility is that women have rapidly achieved parity with men in many aspects of life, including even military roles, leaving men with only their bodies as a distinguishing source of masculinity. Further research will be needed to test these hypotheses.

Several limitations of this study should be considered. First, the heights and weights provided by Playgirl magazine are not verifiable, and may not be entirely accurate. However, any errors in these measurements-unless the errors increased steadily in the same direction over time-would only introduce "noise" into the trends observed and would not invalidate the findings. It should be noted that the previous Playboy studies (Garner et al., 1980; Wiseman et al., 1992) also relied on the measurements supplied by the magazine.

A second possible source of error arises from the visual estimates of body fat. However, the body fat rater (HGP) has performed actual body fat measurements with calipers on more than 600 men in the course of previous studies. Also, in a preliminary study of reliability, HGP was presented with 25 photographs of men of varying body fat, created in the course of a previous investigation. Although HGP had seen these photographs previously, he was blinded to their levels of body fat at the time of the reliability study. In this study, HGP's estimates correlated highly with actual body fat measurements, $r=$ $.90, p<.01$. The mean difference between his estimates and the actual measurements was quite small, $M=-.66, S D=3.73$. Further, it should be recognized that even if the rater's estimates contained large errors, such errors would again only introduce noise into the data, and hence would tend to yield a more conservative finding because the centerfold pictures were presented to the rater under blinded conditions in a randomized order.

Third, we must consider whether the increasing muscularity of Playgirl centerfolds truly reflects an increasingly muscular societal ideal of male body image. For example, it might be argued that female Playgirl readers are not representative of women as a whole. Similarly, it seems likely that a certain number of homosexual men purchase Playgirl, and that these readers may have influenced the evolution of the centerfolds' dimensions. Although these possibilities cannot be excluded, there are no compelling reasons to assume that Playgirl deviates consistently from general male and female preferences for how the ideal male body should look. Furthermore, the parallel data from other studies, such as the increasing muscularity of action toys (Pope et al., 1999), would argue that our findings are indicative of a more general societal trend. 


\section{REFERENCES}

Andersen, A.E., \& DiDomenico, L. (1992). Diet vs. shape content of popular male and female magazines: A dose-response relationship to the incidence of eating disorders? International Journal of Eating Disorders, 11, 283-287.

Blouin, A.G., \& Goldfield, G.S. (1995). Body image and steroid use in male bodybuilders. International Journal of Eating Disorders, 18, 159-165.

Davis, C., Shapiro, M.C., Elliot, S., \& Dionne, M. (1993). Personality and other correlates of dietary restraint: An age by sex comparison. Personality and Individual Differences, 14, 297-305.

Garner, D.M., Garfinkel, P.E., Schwartz, D., \& Thompson, M. (1980). Cultural expectations of thinness in women. Psychological Reports, 47, 483-491.

Gruber, A.J., Pope, H.G., Borowiecki, J.J., \& Cohane, G. (1998, October). The development of the somatomorphic matrix: A bi-axial instrument for measuring body image in men and women. Paper presented at the 1998 Australian Conference of Science and Medicine in Sports, Adelaide, Australia.

Kouri, E.M., Pope, H.G., Katz, D.L., \& Oliva, P. (1995). Fat-free mass index in users and nonusers of anabolicandrogenic steroids. Clinical Journal of Sports Medicine, 5, 223-228.

Leit, R.A. (1998, February). Self-esteem and body satisfaction in men: Men in pursuit of the ideal body. Paper presented at the annual meeting of the Eastern Psychological Association, Boston, MA.

McFarland, R. (Ed.). (1998). Bacon's magazine directory (46th ed.). Chicago: Bacon's Information.

Nemeroff, C.J., Stein, R.I., Diehl, N.S., \& Smilack, K.M. (1994). From the Cleavers to the Clintons: Role choices and body orientation as reflected in magazine article content. International Journal of Eating Disorders, 16, 167-176.

Pope, H.G., Gruber, A.J., Choi, P., Olivardia, R., \& Phillips, K.A. (1997). Muscle dysmorphia: An underrecognized form of body dysmorphic disorder. Psychosomatics, 38, 548-557.

Pope, H.G., \& Katz, D.L. (1994). Psychiatric and medical effects of anabolic-androgenic steroid use. Archives of General Psychiatry, 51, 375-382.

Pope, H.G., Olivardia, R., Gruber, A., \& Borowiecki, J. (1999). Evolving ideals of male body image as seen through action toys. International Journal of Eating Disorders, 26, 65-72.

Wiseman, C.V., Gray, J.J., Mosimann, J.E., \& Ahrens, A.H. (1992). Cultural expectations of thinness in women: An update. International Journal of Eating Disorders, 11, 85-89. 